IDEAS IN ECRLGGY AND EVRLUTION 5: 25-26, 2012

doi:10.4033/iee.2012.5.7.c

(C) 2012 The Author. (C) Ideas in Ecology and Evolution 2012

Received 31 July 2012; Accepted 3 August 2012

Comenentary

\title{
Theory may not be definable and its development is not efficient
}

\author{
Root Gorelick
}

Root Gorelick(Root_Gorelick@carleton.ca), Department of Biology, School of Mathematics \& Statistics, and Institute of Interdisciplinary Studies, Carleton University, 1125 Colonel By, Ottawa ON, CANADA K1S 5B6

Sam Scheiner (2012) raises several very interesting points that are worthy of discussion, even if I disagree with him. These include the following issues in ecology and evolution: (1) the difficulty of defining part of a whole, as we try to do with defining theory as part of science, (2) the putative importance of laws, and (3) whether science should be efficient.

In many disciplines, there exist undefined primitive notions from which other notions are defined and derived. In mathematics, there are undefined concepts, such as of points and lines, as well as seemingly out-of-theblue axioms, such as the parallel postulate and its nonEuclidean alternatives (Lobachevski 1840 [1914]). Theorems and the rest of mathematics are built upon these frameworks. In language, there exists a relatively small set of undefined words from which all other words are defined. Maybe theory is a primitive undefinable notion, as alluded to by Lee Maracle in Cole (2006: 299): "There are a number of words in the English language with no appreciable definition. Argument is defined as evidence; proof or evidence is defined as demonstration or proof; and theory is a proposition proven by demonstrable evidence. None of these words exist outside of their interconnectedness. Each is defined by the other." In a similar sense, Scheiner may be referring to models, hypotheses, and predictions (and theory?) as the undefined constituent parts of the edifice of science.

Theory is hard enough to define, so why confound matters by also introducing laws? Scheiner (2012) makes the brash statement that, "Laws are simply models with four or fewer variables." Who decided on a maximum of four variables? At least Newton's law of universal gravitation,

$$
F=G \frac{m_{1} m_{2}}{r^{2}}
$$

still maintains its status as a law, albeit barely, with four variables. The most famous recent American law, the Patient Protection and Affordable Care Act of 2010 (PPACA; 124 Stat. 119-1025), contains many more than four variables in its 906 pages, although it cleared judicial muster to still be considered a valid law. Because there is no obvious need to define 'laws', there is no reason to care that my "equating theories with predictions places laws outside of those theories".

Scheiner (2012) asserts that we need to do better defining or at least circumscribing fundamental constructs - citing as examples species, individuals, and diversity - because we often have a vague or non-existent notion of these terms that are so central to ecology and evolution. To that end, I have striven to cogently define ecological diversity (Gorelick and Bertram 2010; Gorelick 2011a) and what it means to be an individual (Gorelick 2012).

In his short note, Scheiner (2012) repeatedly emphasizes the need for efficiency in science. This is an odd goal given that science and discovery are not mechanized processes. I believe that scientists and science policy-makers should not strive for efficiency, but rather for creativity. "Creativity requires openness and following intuition, looking at symbols and considering many perspectives, and listening and researching what other people have to say.... A second aspect of the creative process involves thinking in metaphors, that is, in symbols and images." (Cajete 2000: 45). Science is a dramatically and quixotically inefficient process, as the quote from Watterson (1995: 19) in Gorelick (2011b: 7) also demonstrated. Efficiency may be the goal of many bureaucrats, engineers, economists, and factory forepersons, but is counterproductive to progress in science, especially to the development of important new and novel theories. And, fortunately, it is possible to 
quantify progress in developing theories, in ways that emphasize generality and simplicity (Ruse 1996; Chaitin 1997).

Hypotheses need not arise from theory, although I strongly suspect that most productive hypotheses usually have a theoretical basis. Hypotheses are simply declarative statements. Declarative statements can be generated via computer by inputting an allowable set of words and grammatical rules and seeing what arises, vis-à-vis Turing machines and computational grammars. Usually this approach will be utterly unproductive in scientific progress, but on rare occasions such an approach could come up with truly innovative hypotheses.

Finally, Sam Scheiner (2012) seems to have misunderstood my argument about the relationship between theory and models. He implies that I conflate the two, whereas I explicitly outlined a tripartite parsing of science into theory, empirical work, and models, in which 'models' include mathematical and statistical methods (Gorelick 2011b). Let me reiterate this crucial point: Models are not theory, but are the crucial link between theory and empirical work.

\section{References}

Cajete, G. 2000. Native science: natural laws of interdependence. Clear Light Publishers, Santa Fe.
Chaitin, G.J. 1997. The limits of mathematics. SpringerVerlag, Singapore.

Cole, P. 2006. Coyote and Raven go canoeing: coming home to the village. McGill-Queen's University Press, Montréal \& Kingston.

Gorelick, R. 2011a. Do we have a consistent terminology for species diversity? The fallacy of true diversity. Oecologia 167: 885-888. CrossRef

Gorelick, R. 2011b. What is theory? Ideas in Ecology and Evolution 4: 1-10. CrossRef

Gorelick, R. 2012. Mitosis circumscribes individuals; sex creates new individuals. Biology \& Philosophy 27: in press. CrossRef

Gorelick, R. and Bertram, S.M. 2010. Multi-way multigroup segregation and diversity indices. PLoS One 5: e10912. CrossRef

Lobachevski, N. 1840 [1914]. Geometrical researches on the theory of parallels [translator: G. B. Halstead]. Open Court Publishing, La Salle, Illinois.

Ruse, M. 1996. Monad to man: the concept of progress in evolutionary biology. Harvard University Press, Cambridge.

Scheiner, S.M. 2012. The multiple roles of theory: a reply to Gorelick. Ideas in Ecology \& Evolution: 5:22-24. CrossRef

Watterson, B. 1995. The Calvin and Hobbes tenth anniversary book. Andrews and McNeel, Kansas City. 